\title{
STREET FIGHT, VINGANÇA E GUERRA: ARTISTAS INDÍGENAS PARA ALÉM DO "PRODUZIR OU MORRER"
}

\author{
CLARISSA DINIZ1
}

UFRJ, BRASIL

RESUMO: $O$ artigo analisa a inscrição da arte indigena contemporânea no contexto hegemônico da arte brasileira a partir das noções de violência epistêmica, guerra e vingança. No texto, as estratégias performativas e discursivas dos artistas Jaider Esbell e Denilson Baniwa são friccionadas ao Movimento Antropófago e sua historicização, propondo uma reflexão de caráter ético e político.

PALAVRAS-CHAVE: Denilson Baniwa, Jaider Esbell, arte indígena, Movimento Antropófago, antropofagia, Macunaíma, Makunaima, arte contemporânea, arte brasileira, violência epistêmica, vingança, guerra.

ABSTRACT: Based on the notions of epistemic violence, war and revenge, the article analyzes the inscription of contemporary indigenous art in the hegemonic context of Brazilian art. In the text, the performative and discursive strategies of the artists Jaider Esbell and Denilson Baniwa are interposed against the Anthropophagic Movement and its historicization, proposing an ethical and political reflection.

KEYWORDS: Denilson Baniwa, Jaider Esbell, indigenous art, Movimento Antropófago, cannibalism, Macunaíma, Makunaima, contemporary art, Brazilian art, epistemic violence, revenge, war.

\footnotetext{
${ }^{1}$ Professora da Escola de Artes Visuais do Parque Lage e doutoranda em antropologia pelo Programa de Pós-Graduação em Antropologia e Sociologia da Universidade Federal do Rio de Janeiro. E-mail: clarissa.diniz@gmail.com
} 


\section{Introdução}

É patente que, nos últimos anos, o Brasil tem vivenciado um processo até então quase inexistente: a verificação da presença de artistas indígenas no âmbito da arte contemporânea que, como tal, é marcadamente euroetnocêntrica. Como se depreende sem dificuldades, esse movimento é menos elucidativo de um "sistema de arte próprio [aos indígenas], com sentidos e dimensões próprios" (ESBELL, 2019, p.98), do que sintomático no que tange à compreensão dos modos de operação e de produção de sentido da genericamente autodenominada "arte", a qual cabe adjetivar como europeia, branca e burguesa. Pois, se "indígena e arte são de origem indissociável" - e, portanto, como adverte o artista makuxi Jaider Esbell, "a arte entre os indígenas hoje brasileiros vêm desde antes de [falarmos da ideia de país]" -, quando a "arte indígena encosta na arte geral enquanto sistemas próprios, (...) elas não se fundem nem se confundem totalmente" (ESBELL, 2019, p.100).

É nesse sentido que, ao partirmos do pressuposto da singularidade deste momento histórico no que tange à representação política dos indígenas na arte enquanto presença dos mesmos em seu complexo sistema social e econômico (do que é um exemplo que, em 2016 e em 2019, dois artistas indígenas - Jaider Esbell e Denilson Baniwa - tenham sido os vencedores do Prêmio PIPA na categoria online, um dos mais relevantes do país), não devemos, por outro lado, obliterar sua histórica e reiterada presença enquanto objeto, imagem, tema. Assim, dado que hoje legitimamos a ideia de "um encontro da arte contemporânea indígena com o sistema de arte global", Jaider Esbell propõe que encaremos o que foi o encontro historicamente posto: "o indígena aparece primeiro nas cartas enviadas para a Europa, logo após a chegada dos primeiros navios. Ele aparece em representações de artistas europeus numa cena de primeira missa. Assim é o encontro do sistema de artes europeu com os artistas selvagens. (...) O indígena é posto para cantar na catequese, é posto a ilustrar documentos de pesquisadores das mais diversas áreas do conhecimento. Sobre esses artistas pouco é falado" (ESBELL, 2019, p.101).

Ao forjar uma espécie de 'marco zero' historiográfico no evidentemente 'inédito' - em termos de reconhecimento de autoria fenômeno de inscrição da arte indígena no campo hegemônico da arte, nossa perspectiva etnocêntrica reencena a violência originária desse processo, iniciado, no que tange às Américas, em 1492. Atribuir agência exclusivamente aos artistas indígenas que hoje, "por força própria" (ESBELL, 2019, p.100), performam essa inscrição é sustentar a perspectiva racista da ideia de que, quando eram "somente" objetos, imagens, temas, os indígenas não estavam agindo.

\section{Denúncia}

Em dezembro de 2017, realizou-se, no Instituto Goethe de São Paulo, um encontro entre um pequeno grupo de indígenas, curadores, 
antropólogos e pesquisadores interessados em processos de troca, interlocução e colaboração entre práticas artísticas indígenas e institucionais, reunidos durante dois dias com a intenção de discutir os cuidados e os limites éticos, políticos e epistêmicos implicados nessas relações.

Dentre as diversas discussões, fez-se uma denúncia coletiva, endereçada por Ailton Krenak: "Mário de Andrade fez o sequestro relâmpago bem-sucedido do Makunaima. E até hoje tudo que se reproduz ainda vem daí. Ele parece ter feito uma coisa imbatível e por isso é interessante querer retornar, fazer um street fight com Mário de Andrade. (...) A apropriação de um ovo em ninho alheio é uma batalha monumental, que merece ser confrontada. É preciso denunciar a arte moderna" (KRENAK, 2017).

\section{Substituição}

O bem-sucedido sequestro de Makunaima faz-se ouvir, por exemplo nos ecos da recente crítica do historiador, curador e professor Tadeu Chiarelli à exposição Tarsila Popular (realizada este ano no Museu de Arte de São Paulo Assis Chateaubriand, MASP) quando, ao referir-se à pintura Batizado de Macunaíma (1956), afirma que a pintora "parece ter desejado elevar o personagem criado em 1928, por Mário de Andrade, ao patamar de um símbolo" (CHIARELLI, 2019). Conquanto o batismo da pintura seja conduzido por indígenas em meio à mata, o crítico parece ter lido o Macunaíma em questão estritamente como o personagem de Mário de Andrade, ainda que, já em parte adiantada da referida rapsódia, este tenha sido batizado pelo "índio Antônio" não na floresta, mas numa pensão².

Mário de Andrade era leitor de Theodor Köch-Grunberg, etnógrafo alemão que esteve quatro vezes no Brasil no começo do século XX e que coletou e publicou, em De Roraima ao Orinoco (1916), relatos sobre Makunaima, interpretando-o - como já o haviam feito os missionários jesuíticos - como Deus pelas equivalências forçosamente estabelecidas entre as cosmologias ameríndias e aquelas cristãs ao longo da colonização. O escritor apropriou-se, desse modo, da entidade indígena que habita o Monte Roraima, Makunaima, para criar essa que é decerto uma das principais alegorias já produzidas sobre o Brasil.

O descompromisso de Mário de Andrade com Makunaima revela-se quando concebe Macunaíma como um indígena negro, marcado pela indolência e cuja potência de criação é, na narrativa modernista, circunscrita como uma personalidade "sem nenhum caráter". Sequestrando Makunaima e reinterpretando-o a seu bel prazer, Mário e o incalculável legado cultural, social e político construído a partir de sua obra acabou, como se percebe através da obliteração de qualquer

\footnotetext{
2 "Foi visitar Macunaíma, fez discurso e batizou o herói diante do deus que havia de vir e tinha forma nem bem de peixe nem bem de anta. Foi assim que Macunaima entrou pra religião Caraimonhaga que estava fazendo furor no sertão da Bahia." (ANDRADE, 1928, p.96)
} 
referência à entidade indígena não só na crítica de Chiarelli, como na quase totalidade das reflexões da história da arte brasileira acerca do Batizado de Macunaíma de Tarsila do Amaral, substituindo aquilo que supostamente representava.

\section{Violência epistêmica}

A hegemonia, modelo civilizatório da modernidade que engendrou imperialismos e colonialismos de toda ordem, produziu processos de epistemicídio: a destruição maciça de experiências e conhecimentos subordinados, considerados inadequados para servir ao projeto colonial (SANTOS, 2017). O epistemicídio integrou e viabilizou, desde os imaginários, a economia da escravidão e da subalternização do outro, tornando-se parte inextricável do genocídio.

Após a independência das colônias e a transformação dos modos de operação da colonização, o epistemicídio persiste enquanto política de aniquilação da diversidade, bem como em formas complexas de violência epistêmica: "a alteração, a negação e em casos extremos como o das colonizações, a extinção dos significados da vida cotidiana, jurídica e simbólica de indivíduos e grupos" (BELAUSTEGUIGOITIA, 2001, p.237). A violência epistêmica é uma forma de invisibilização do outro cuja operação central é retirar-lhe a possibilidade de (auto)representação através da "anulação tanto dos sistemas de simbolização, subjetivação e representação que o outro tem de si mesmo, como das formas concretas de representação, registro e memória de sua experiência" (BELAUSTEGUIGOITIA, 2001, p.238), produzindo silêncios. Por meio da hegemonia e em nome da universalidade da razão, "foi de fato imposta a razão de uma raça, de um sexo e de uma classe social", produzindo "silêncios que tornaram impronunciáveis as necessidades e aspirações de povos ou grupos sociais cujas formas de saber foram objeto de destruição" (SANTOS, 2007, p.30).

A violência epistêmica é, contudo, de mais difícil percepção do que o epistemicídio por se dar através do duplo do silenciamento, a representação. Representar (Vertretung) é também substituir: "a representação como "falar por" como na política e a "re-presentação", como aparece na arte ou na filosofia (...) são sentidos relacionados, mas são irredutivelmente descontínuos" (SPIVAK, 1988, p.32). O que torna a discussão especialmente problemática no âmbito da arte é precisamente a sobreposição entre os dois sentidos da representação que, entrecruzados, por sua vez, elevam os riscos de violência.

Enquanto alguns epistemicídios são facilmente identificados, há outros "revestidos de justificações para ocultar a violência da imposição de uma cultura ou universo simbólico". Por exemplo, “(...) esquemas de equivalências [entre elementos culturais similares] possibilitaram práticas de ressemantização funcional" (DO BEM, 2008, p.79) que histórica - como atualmente - serviram para salvaguardar hegemonias, processos para os quais concorreram inclusive ideias de educação (e evangelização) cuja 
violência era apresentada como sacrifício salvador em benefício dos colonizados (DUSSEL, 2000).

Essa circunscrição ética e política assemelha-se àquela da arte, que sempre operou para a "invenção do outro" e que, atualmente, se mantém produzindo interesse e demanda pela alteridade, movimento que, no Brasil, integra as lutas por representatividade e participação políticas. $O$ que vemos, nesse exercício de expansão e inclusão de perspectivas não etnocêntricas na arte, é a falta de engajamento efetivo com os universos e epistemologias indígenas (que, na sua diversidade, são constantemente reduzidos a um todo unificado) e seus próprios modos expressivos (CESARINO, 2016) em sua maioria violentando as culturas indígenas sob leituras anônimas e a-históricas, dessubjetivando-os por meio de seus próprios objetos.

\section{Deixar-se ir}

Não obstante, Makunaima resistiu e, por meio de seu neto e artista Jaider Esbell, adverte-nos que, por saber "da importância dos ícones na cultura que havia chegado" (ESBELL, 2018, p.17), diante dos invasores, para salvar os seus, escolheu a "máxima exposição". "Deixou-se ir" entregando-se como "caça aos caçadores". "Eu grudei na capa daquele livro" de Mário de Andrade: "Dizem que fui raptado, que fui lesado, roubado, injustiçado, que fui traído, enganado. Dizem que fui besta. Não! Fui eu mesmo que quis ir na capa daquele livro. Fui eu que quis acompanhar aqueles homens. Fui eu que quis ir fazer a nossa história. Vi ali todas as chances para a nossa eternidade" (ESBELL, 2018, p.18).

A operação de Makunaima parece ter sido eficaz. Se, por semelhança, o ícone substitui aquilo que representa, na violência da apropriação que iconiza incide também alguma permuta entre a captura e a liberdade. Suprido por sua versão icônica, depois de ter se "deixado ir", Makunaima deve ter retomado sua deriva de contínua transformação. Como conta seu neto Makuxi, "Makunaima sabia sempre o que fazia": "Vi vocês no futuro. Vi e me lancei. (...) Estive na margem de todas as margens, cheguei onde nunca antes nenhum de nós esteve. Não estive lá por acaso. Fui posto lá para nos trazer até aqui" (ESBELL, 2018, p.16).

É assim que, na virada para a terceira década do século XXI, as netas e netos de Makunaima aportam de todos os lados não somente para corrigir as leituras equivocadas dos invasores que têm estado há muito empenhados em sua captura - "seria um risco se estivéssemos pleiteando compreensão" (ESBELL, 2018, p.35) -, mas para afirmar a inesgotabilidade das transformações de Makunaima, a impossibilidade de reduzir ou capturá-las e, portanto, para gozar do poder de ser parte inextricável desse movimento de vida e criação: "tanto meu avô Makunaima quanto eu mesmo, parte direta dele, somos artistas da transformação" (ESBELL, 2018, p.11).

Como aponta Jaider Esbell, "o buraco é mais embaixo" (ESBELL, 2018 b) pois "não há como discutir decolonização" sem "adentrar as portas das cosmovisões dos povos originários" (ESBELL, 2018, p.13). E, 
como não há como adentrá-las sem de algum modo reencenarmos a invasão, é sobre essa incontornável e radical diferença que se sustenta a posição política do futuro que Makunaima cultivou para seus descendentes: deixando-se iconizar pela modernidade branca, agora dá a ver que o Brasil - e a arte brasileira - que se constituíram sobre a violação das cosmopolíticas ameríndias só podem sustentar seus cânones e mitos expropriadores se, em muitos níveis, perversamente se mantiver conivente com as práticas coloniais, atualizando-as.

\section{Ameaça}

Noventa anos depois da publicação de Macunaíma de Mário de Andrade (escrito, todavia, dois anos antes, em 1926) e do Manifesto Antropófago (1928) de Oswald de Andrade, dois dos marcos centrais da arte moderna no Brasil e que, não coincidentemente, se fizeram por meio de sequestros de elementos diversos das cosmopolíticas ameríndias, é justamente a problematização da violência epistêmica produzida pela arte que bate à nossa porta:

"o mundo branco vai fazer parte de nossas vidas para sempre. Não há condição nenhuma de separar esses mundos. E o mundo artístico é muito complicado para nós. Mas a arte contemporânea indígena veio para ficar. $E$ isso é um compromisso meu; é a história da minha vida: arte, ativismo e projeto intelectual. (...) Temos que estar atentos para não sermos usados" (ESBELL, 2017).

Diante do processo histórico que nos conduziu até aqui, como adverte Jaider Esbell, os artistas indígenas que forçam e movem a atual inscrição de sua produção no campo da arte contemporânea em sua versão hegemônica estão se cuidando e forjando estratégias para reagir à apropriação, à expropriação, ao extrativismo, à exotização, à invisibilização, à fetichização, à mais-valia, etc., que até então têm identificado a aproximação, quase sempre uma abordagem primitivista, perpetrada pela arte em relação às culturas indígenas. Como dá a ver o tom assertivo do artista makuxi, essa atenção ético-política não se dá, por sua vez, em chave pacifista, como se a arte e sua branquitude violadora finalmente estivessem recebendo, de braços abertos, o "bom selvagem".

Trata-se, antes, de uma presença intimidadora. Opositores da presunção de passividade que, incapaz de perceber agência onde nossa iconofilia só enxerga imagem, tem sido - do século XV à história da arte atual - persistentemente atribuída aos "índios", vários são os artistas indígenas que se sentem "em atuação performática para além do figurativo": "a arte indígena chega em ícones corporificados e depurados em uma trajetória de representação até um estado pleno de identidade cosmo-consciente" (ESBELL, 2019, p.102). Presentes, os ícones corporificados ameaçam, portanto, os ícones que - como a arte moderna brasileira - historicamente os suprimiram ao julgar representá-los: “De 
repente, a antropofagia da arte está aqui. Com os antropófagos de verdade. Nós somos os antropófagos de verdade e nós vamos devorar e regurgitar essa arte - desenhando, que é assim que vocês entendem", advertiu Denilson Baniwa naquele mesmo encontro no Instituto Goethe.

\section{Culturalização da antropofagia}

Performando a antropofagia desde a perspectiva da arte, Denilson Baniwa e Jaider Esbell fazem "política de resistência declarada com a arte em contexto contemporâneo aberto" (ESBELL, 2019, p.103), o que implica "falar de direito à terra e à vida" (ESBELL, 2019, p.98). Evidenciando uma prática criadora que se dá para além do cânone da arte eurocêntrica, descartam a hipótese de autonomia da arte moderna e sua ficcional constituição de uma agenda estética própria, capaz de descolar-se da vida. Ao fazê-lo, produzem também antagonismo político face à culturalização da antropofagia, interpretada, desde o saque modernista, como prática de construção de identidade cultural sem, todavia, enfrentar seu fundamento sócio-jurídico - a relação com a terra e a vida -, do que são índice seus constantes esvaziamentos políticos em prol de uma narrativa culturalista.

Imagem 1: Obama, Dilma Rousseff e Michelle Obama posam com obra de Tarsila em 2011

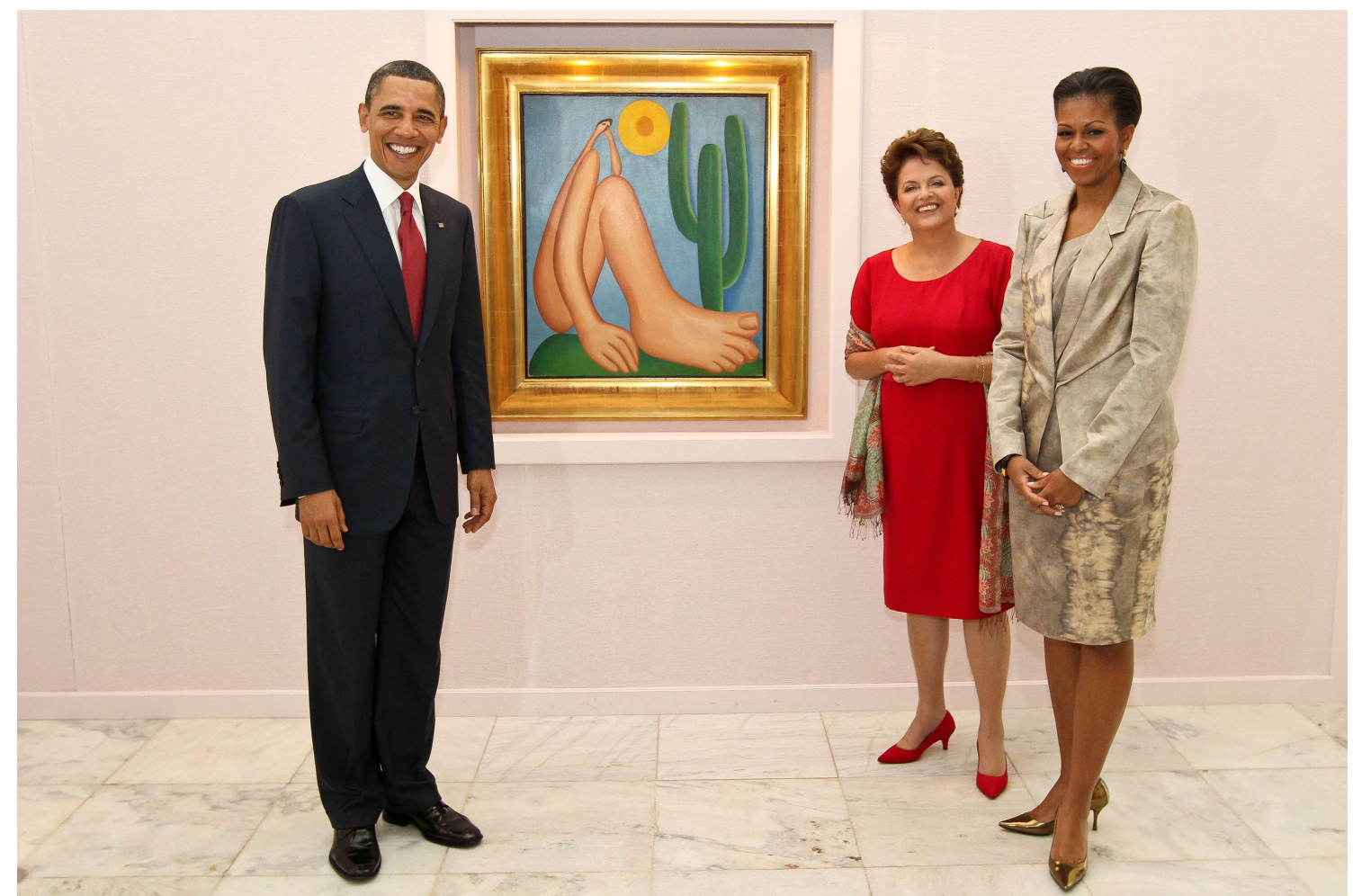

Fonte: https://noticias.r7.com/brasil/fotos/fa-das-artes-dilma-abre-as-portas-do-planalto-paraobras-de-romero-britto-tarsila-do-amaral-e-caravaggio-09102013? foto=5\#!/foto/5) 
Em 2011, Dilma Rousseff trouxe a pintura Abaporu (1928), de Tarsila do Amaral - pertencente ao acervo do Museu de Arte Latinoamericano de Buenas Aires ${ }^{3}$ - de volta ao Brasil para receber Barack Obama, exibindo-a no Palácio do Planalto enquanto pedia apoio político à candidatura do Brasil a um assento permanente no Conselho de Segurança da ONU. Na visita, justificava que

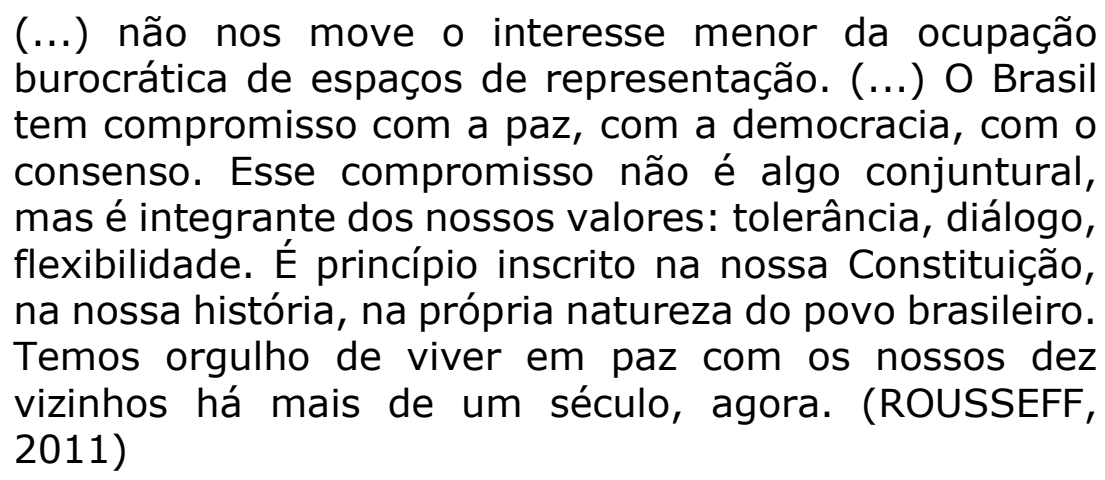

Como ficava evidente no discurso da presidenta, a demanda por apoio político vinha acolchoada por uma abordagem culturalista ancorada na pintura de Tarsila - apresentada como ícone nacional ainda que não pertencesse mais ao Brasil - e na interpretação de que o "Movimento Antropofágico é a nossa capacidade de absorver o que tem de universal em todas as culturas e metabolizar no particular" (ROUSSEFF, 2011).

No primeiro número da Revista de Antropofagia (1928), Oswald de Andrade publicava o Manifesto Antropófago, um texto fundamental à construção do que hoje chamamos de Brasil, cuja força simbólica e política parece renovar-se quando, em 2018, o Museu de Arte Moderna de Nova lorque (MoMA) realiza a exposição retrospectiva Tarsila do Amaral: inventing modern art in Brazil ${ }^{4}$ ou quando, no ano seguinte, com a mostra Tarsila Popular, o MASP bate seu recorde de público ${ }^{5}$ : fenômeno de popularização e valorização que é também inseparável das dinâmicas do capitalismo e do mercado de arte, apontando para a complexidade histórica, social, política e estética experimentada pela "arte brasileira" e suas representações. Não é de hoje, entretanto, a leitura reducionista das intenções e das estratégias do projeto antropofágico perpetrada pelo

\footnotetext{
${ }^{3}$ Após pintada, Abaporu deve ter permanecido no seio do núcleo Amaral até 1964, quando foi vendida ao colecionador Érico Stickel através da mediação da Galeria Mirante das Artes (SP), cujos proprietários eram Giuseppe Baccaro e o diretor do Museu de Arte de São Paulo, Pietro Maria Bardi. Em 1984, Stickel vende a obra a Raul Forbes, por US\$ 250 mil e, após de dez anos em sua coleção, Raul repassa Abaporu a Eduardo Constantini, o colecionador argentino que, presidente do Museu de Arte Latinoamericana de Buenos Aires, torna a tela uma propriedade não mais brasileira.

${ }^{4}$ Com a exposição Tarsila do Amaral: inventing modern art in Brazil (2018), o Museu de Arte Moderna de Nova Iorque realizou uma leitura reducionista das intenções e das estratégias do projeto antropofágico em consonância à culturalização que o movimento vem sofrendo no Brasil: "anthropophagy is a transformative artistic movement which imagined a specifically Brazilian culture arising from the symbolic digestion - or artistic "cannibalism"- of outside influences". Disponível em: https://www.moma.org/calendar/exhibitions/3871?locale=en. Acessado em 2 de agosto de 2019.

${ }^{5}$ Com Tarsila Popular e seus 402.850 visitantes, o MASP superou inclusive a audiência de mostras de artistas como Monet (1997), Picasso (1999) ou Salvador Dalí (1998).
} 
processo de "culturalização" que não só a prática da antropofagia, como também o Movimento Antropófago, vêm sofrendo no Brasil.

Como, até a década de 1950, a antropofagia encontrava-se marginalizada, a montagem da peça $O$ Rei da Vela (1933) pelo Teatro Oficina em 1967 teve papel fundamental na reabilitação política e estética da obra de Oswald de Andrade e, em especial, de seu projeto antropofágico. Em pleno regime militar, os argumentos dos modernistas antropófagos brancos foram usados contra as conservadoras ideias nacionalistas, racistas e xenófobas então em voga, do que foi índice a Marcha Contra a Guitarra Elétrica (1967) promovida em São Paulo. A partir de então, a antropofagia da década de 1920 passou a ser lida (quase que exclusivamente) à luz da apropriação que dela fez a geração da Tropicália ${ }^{6}$, responsável por nevrálgicas transformações na cultura do país nas décadas de 1960 e 1970.

Imagem 2: Outdoor da 24a Bienal Internacional de Artes de São Paulo

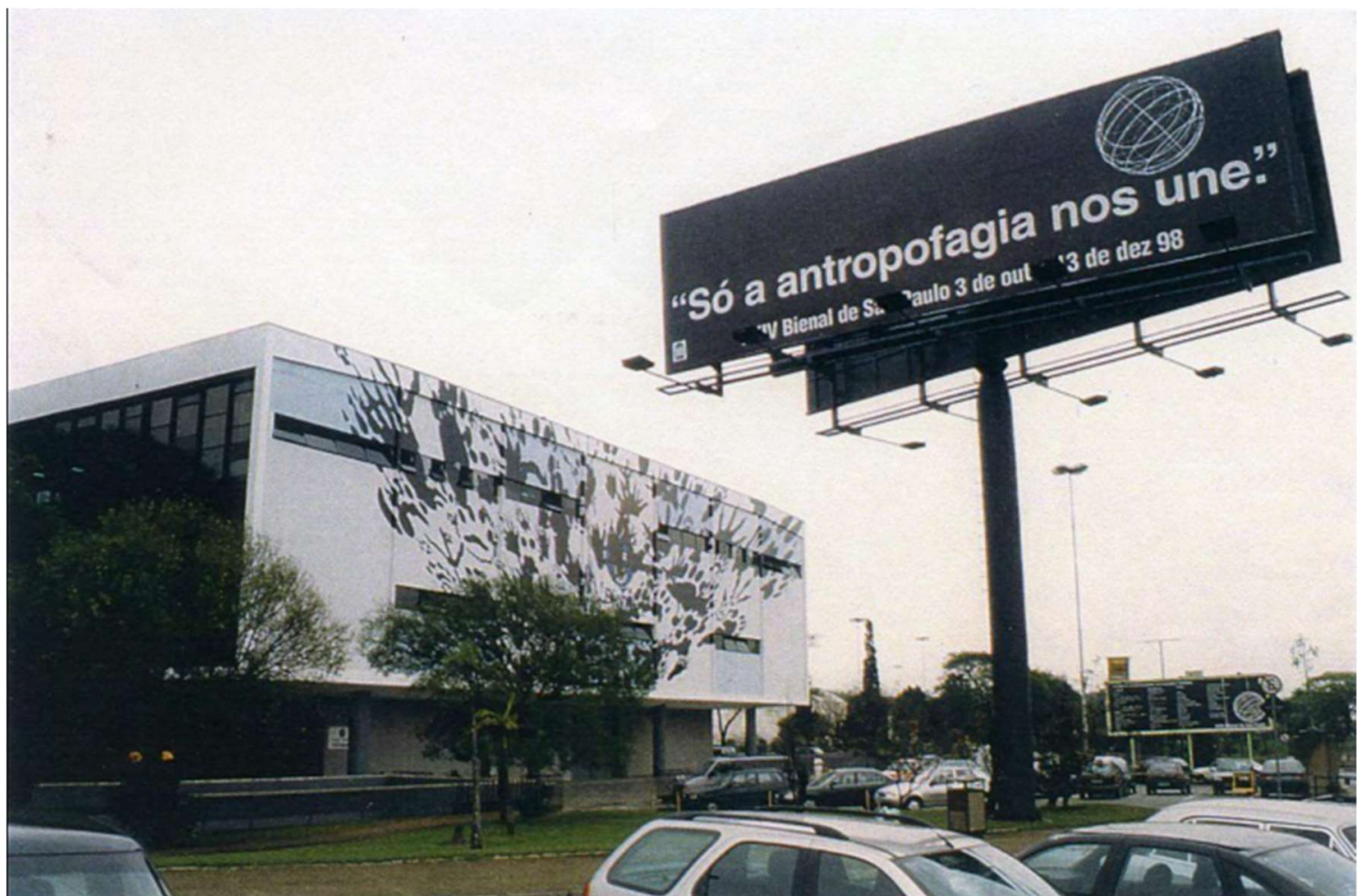

Fonte: http://www.forumpermanente.org/event pres/cursos-disciplinas/deslocando-o-canonecuradoria-como-historia-na-arte-da-america-latina/24a-bienal-de-sao-paulo

Décadas mais tarde, em 1998, a 24ª Bienal de São Paulo propôs a antropofagia como um conceito central para a arte brasileira e, mais ambiciosamente, como a principal contribuição do país para a arte do século $X X$ em todo o mundo. A leitura culturalista do pensamento

\footnotetext{
${ }^{6}$ Entre 1967 e 1969, além de José Celso Martinez Corrêa, também Hélio Oiticica, Glauber Rocha, Jommard Muniz de Brito e Torquato Neto escreveram espécies de manifestos que quarenta anos depois dialogavam com o texto de Oswald de Andrade, quase sempre interpretando o Manifesto como "identidade nacional", ainda que não essencialista, como sintetizava Oiticica: "a célebre conclusão de que seria nossa cultura antropofágica, ou seja, redução imediata de todas as influências externas a modelos nacionais" (Esquema Geral da Nova Objetividade, 1967).
} 
antropofágico da década de 1920 permaneceu intacta na abordagem da exposição, como demonstrava Paulo Herkenhoff, seu curador: "eu queria que a [Bienal] tivesse um ponto de partida traçado a partir da cultura brasileira, mas entendendo que a nossa cultura é filiada à cultura ocidental, mas com tensões, diferenças e singularidades" (HERKENHOFF, 1998). Como fica evidente com o uso da expressão "nossa cultura", além da culturalização da antropofagia, a interpretação produzida no seio do campo da arte fixava a "identidade nacional" como sua problemática central. A afirmação de uma interpretação unionista da antropofagia vide o trecho do Manifesto que foi escolhido como publicidade da $24^{\mathrm{a}}$ Bienal ("só a antropofagia nos une") - alcançou o circuito internacional da arte, configurando-se como leitura hegemônica do projeto antropofágico e como uma espécie de traço identitário da "cultura nacional", quase sempre caracterizada como harmoniosa e pacífica, do que se valeu Dilma Rousseff em sua operação diplomática junto ao Abaporu.

Entretanto, por meio de sua culturalização tem-se sistematicamente apagado a dimensão política e social do projeto antropofágico, em cujo Manifesto Antropófago já havia, por exemplo, mais citações ao direito e a aspectos jurídico-sociais do que à arte ou alguma identidade cultural específica: "única lei do mundo", "tínhamos a justiça codificação da vingança", "perguntei ao homem o que era o Direito", "direito sonâmbulo", "o pater familias e a criação da Moral da Cegonha", "matriarcado de Pindorama", etc. Como analisa a brilhante tese de Alexandre Nodari , o que a leitura culturalista não considera densamente é a elaboração não de um projeto de identidade, mas de um direito antropófago, esforço que esteve em curso nos curtos anos em que durou a Revista de Antropofagia (1928-1929), cuja máxima tornou-se "a posse contra a propriedade".

Nesse sentido, o grupo dos modernos antropófagos apropriou-se do complexo do canibalismo guerreiro ameríndio (VIVEIROS DE CASTRO, 2011), - à época circunscrito por Oswald de Andrade como "um sistema social-planetário" e "Weltanschauung canibal" - não para dele extrair aspectos identitários ou um modus operandi para responder às culturas estrangeiras, senão para inventar uma poética e uma política que era sobremaneira uma crítica radical à concepção positivista (como tal, euro e etnocêntrica) do "Sujeito" enquanto unidade fixa, coincidente consigo mesma: "Só me interessa o que não é meu. (...) Nunca admitimos o nascimento da lógica entre nós. (...) Antropofagia. A transformação permanente do Tabu em Totem. Contra o mundo reversível e as ideias objetivadas. Cadaverizadas" (ANDRADE, 1928).

O gesto anti-colonial da produção político-poética da Revista de Antropofagia foi o de apontar a dimensão arbitrária e ficcional da episteme jurídica e social do colonizador (criticando suas instituições fundantes) e a violência política, social e epistêmica da colonização enquanto saque territorial ("o Brasil é um grilo de 6 milhões de quilômetros talhado em Tordesilhas") e cultural ("sem nós, a Europa não

\footnotetext{
${ }^{7}$ Cf. Nodari, Alexandre André. A posse contra a propriedade: pedra de toque do direito antropofágico. Dissertação (mestrado) - Universidade Federal de Santa Catarina, Centro de Comunicação e Expressão. Programa de Pós-Graduação em Literatura, 2007. Disponível em: http://repositorio.ufsc.br/xmlui/handle/123456789/89601
} 
teria sequer sua pobre declaração dos direitos do homem") (ANDRADE, 1928). Esses argumentos delinearam sua crítica ao colonialismo, instituindo, como seu principal corolário, a proposição de outra epistemologia social, de fundamentos indígenas: o matriarcado contra o patriarcado, a posse contra a propriedade, a adivinhação contra a especulação, dentre outros "preceitos".

A antropofagia não foi, dessa forma, utilizada como dispositivo conceitual para endereçar identitária e pacificamente a violência da colonização - como havia dito a presidenta Dilma Rousseff -, mas seu avesso: um constructo anti-colonial cuja rebeldia epistêmica sublinhava a legitimidade, a importância e a necessidade da constituição de epistemologias distintas, e não desviantes, das coloniais. Seu gesto vertebral não foi o de "filiar nossa cultura à cultura ocidental", senão seu oposto - o de apontar o 'falso problema epistêmico' derivado do processo histórico da colonização, a saber: a sensação de que teríamos que nos constituir em relação ao 'estrangeiro'. Por isso o cuidado central da narrativa temporal-histórica do Manifesto Antropófago, evidente na adoção de outros marcos (como a caracterização de 1928 como sendo o "ano 374 da deglutição do bispo Sardinha") e o uso continuado de expressões de antecipação ao marco fundador do discurso colonial, a "descoberta", como "já tínhamos o comunismo", "sabíamos transpor o mistério e a morte com o auxílio de algumas formas gramaticais", "antes dos portugueses descobrirem o Brasil, o Brasil tinha descoberto a felicidade" (ANDRADE, 1928).

A proposição anti-colonial antropófoga foi, entretanto, persistentemente colonial em suas dinâmicas de apropriação e extrativismo em relação aos povos indígenas, produzindo violências epistêmicas contra aqueles que, por sua vez, estavam sendo convocados para uma luta contra a hegemonia colonial e seu característico epistemicídio. Ainda que, em 1933, no prefácio de Serafim Ponte Grande, o próprio Oswald de Andrade tenha reconhecido parte do problema político, ético, social e estético das contradições da Antropofagia achincalhada por ele como "sarampão antropofágico"- do ponto de vista da luta de classes $^{8}$, escapam à sua percepção, contudo, as violências epistêmicas por ela produzidas no que se refere aos povos indígenas, os sujeitos cujo conhecimento foi apropriado por Oswald e seus interlocutores para a elaboração do direito antropófago. Há, por isso, necessidade de vingança.

\footnotetext{
8 "A situação "revolucionária" desta bosta mental sul-americana, apresentava-se assim: o contrário do burguês não era o proletário - era o boêmio! As massas, ignoradas no território e como hoje, sob a completa devassidão econômica dos políticos e dos ricos. Os intelectuais brincando de roda. (...) Fui (...) um palhaço de classe. (...) Continuei na burguesia, de que mais que aliado, fui índice cretino, sentimental e poético. (...) Quem sabe se a alta do café não ia colocar a literatura nova-rica da semicolônia ao lado dos custosos surrealismos imperialistas? (...) A valorização do café foi uma operação imperialista. A poesia Pau-Brasil também. Isso tinha que ruir com os cometas da crise. Como ruiu quase toda a literatura brasileira "de vanguarda", provinciana e suspeita, quando não extremamente esgotada e reacionária." (ANDRADE, 1933)
} 
Espaço Ameríndio

\title{
Vingança
}

Nos últimos anos, instituições e iniciativas de arte têm sido surpreendidas pelo pajé-onça, entidade criada pelo artista Denilson Baniwa, que interveio, por exemplo, na $33^{\text {a }}$ Bienal de São Paulo, na qual, diante de uma gigantesca fotografia etnográfica de indígenas Selk'nam, desfolhou o livro Breve história da arte enquanto provocava e questionava o público da Bienal e a própria instituição da arte:

Breve história da arte. Tão breve, mas tão breve, que não vejo a arte indígena. Tão breve que tem indígena nessa história da arte. Mas eu vejo índios nas referências, vejo índios e suas culturas roubadas. Breve história da arte. Roubo. Roubo. Roubo.

Isso é o índio?

Aquilo é o índio?

É assim que querem os índios? Presos no passado, sem direito ao futuro?

Nos roubam a imagem, nos roubam o tempo e nos roubam a arte.

Breve história da arte. Roubo, roubo, roubo, roubo, roubo, roubo, roubo. Arte branca. Roubo, roubo.

Os índios não pertencem ao passado. Eles não têm que estar presos a imagens que brancos construíram para os índios.

Estamos livres, livres, livres. Apesar do roubo, da violência e da história da arte. Chega de ter branco pegando arte indígena e transformando em simulacros!

(BANIWA, 2018)

Como se percebe nas falas e nos gestos de Jaider Esbell e Denilson Baniwa, eles estão "nos" intimidando. A sua resistência, bem como sua emergência no campo da arte contemporânea, não se dá como bandeira branca. Sua presença no território privilegiado da branquitude - a arte contemporânea - é, necessariamente, um movimento anti-colonial que se faz em reação às violências epistêmicas de que foram e de que continuam sendo alvos e, por isso, se dá como vingança, como avisa Baniwa:

\author{
Quem eu sou? \\ Eu sou o medo dos brancos \\ Eu sou aquele que senta na mesa dos doutorados \\ Que desestabiliza e causa constrangimento a todos \\ Que ri do vocabulário prolixo e do currículo lattes dessa \\ gente branca \\ Eu sou o novo cabano \\ Eu sou a resistência através da antropofagia \\ Eu sou aquele que degola Tarsila do Amaral \\ Eu sou aquele que empala Mário de Andrade \\ Eu sou aquele que come o coração de Oswald de Andrade \\ Eu sou a arte Indígena \\ Eu sou o Indígena contemporâneo
}


Muito prazer

(BANIWA, 2018b)

A disposição cosmopolítica de vingar a violência epistêmica produzida pela arte moderna é a coluna vertebral da pintura ReAntropofagia (2019), uma alegoria de Denilson Baniwa acerca desse inédito processo em curso: sobre uma bandeja, vemos a cabeça enegrecida de Mário de Andrade, decepada, ao lado de mandioca, milho, café, pimenta, da $1^{\text {a }}$ edição de Macunaíma e de um bilhete no qual se lê "aqui jaz o simulacro Macunaíma. Jazem juntos a ideia de povo brasileiro e a antropofagia temperada com bordeaux e pax mongolica. Que desta longa digestão renasça Makunaimî e a antropofagia originária que pertence a todos nós, indígenas".

Imagem 3: ReAntropofagia. Pintura de Denilson Baniwa (2019)

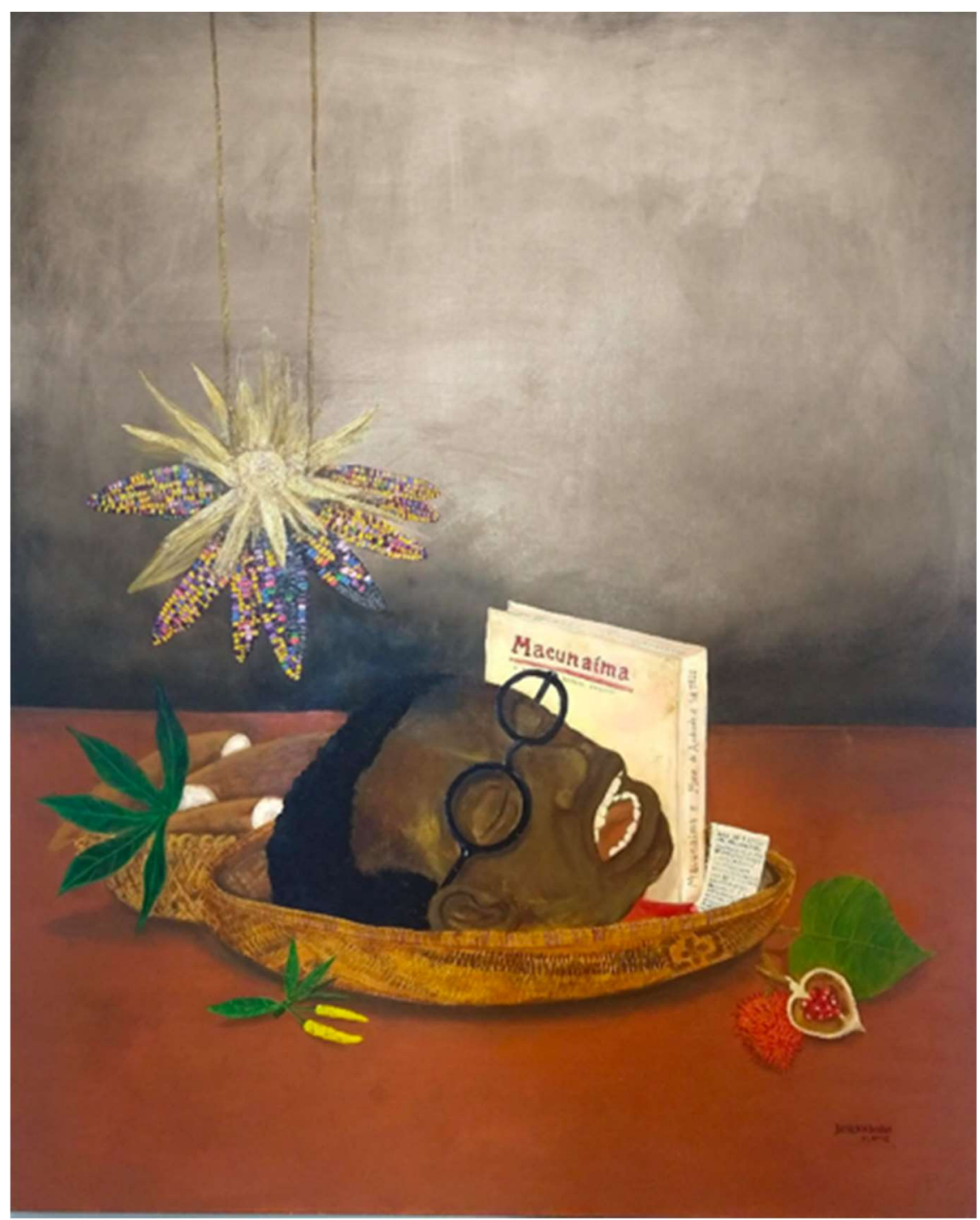

Fonte: Acervo do artista 
Imagem 4: ReAntropofagia [detalhe]. Pintura de Denilson Baniwa (2019).

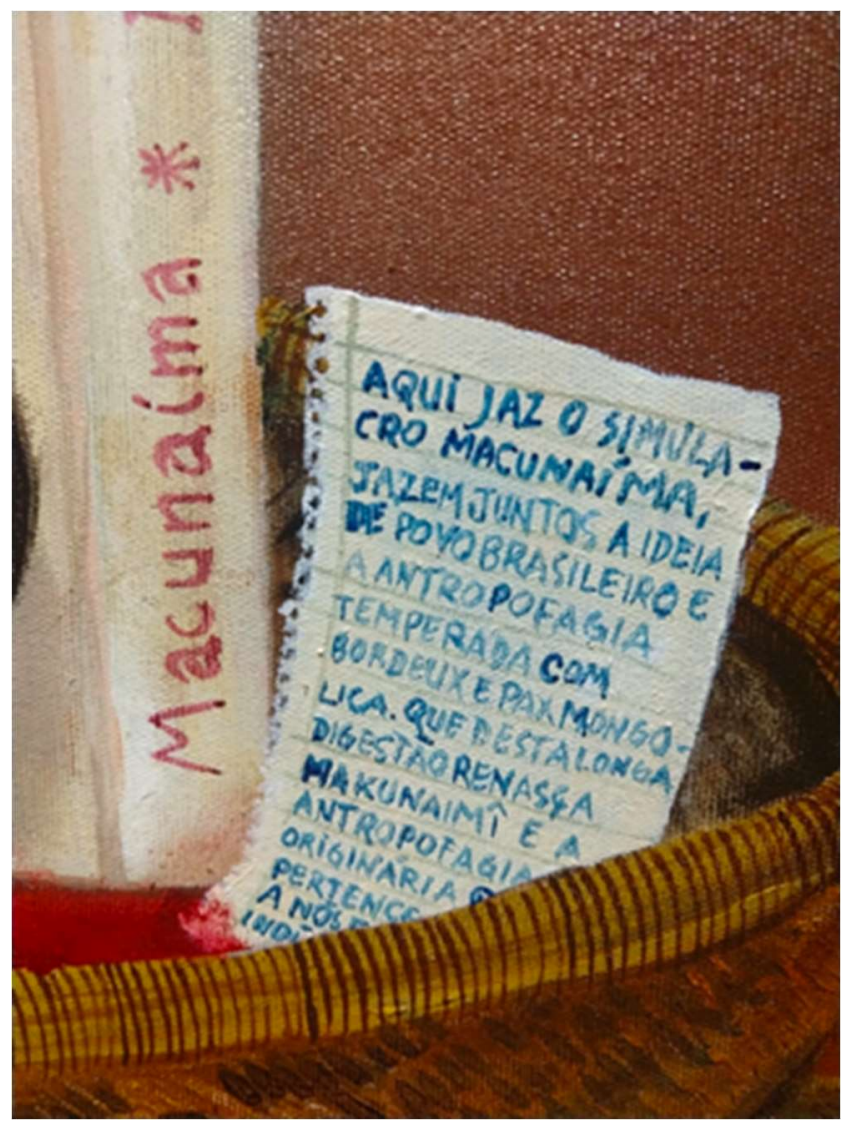

Fonte: Acervo do artista

A pintura integrou a exposição homônima, organizada em abril de 2019 no Centro de Artes da Universidade Federal Fluminense, sob curadoria de Denilson e Pedro Gradella, reunindo artistas contemporâneos indígenas: "aqueles que descendem dos antigos antropófagos de Pindorama vêm a público falar que daquele fundo do mato-virgem, de uma preguiça repetida por aquela antropofagia que uniu apenas aqueles que tomaram a Nossa História na voz de Mário de Andrade, ressurge a ReAntropofagia, um Manifesto, um grito de urgências sobre a arte produzida pelos povos originários, quebrando assim séculos de silenciamento e exotização dos que sempre estiveram aqui" (BANIWA e GRADELLA, 2019).

Que haja violência nessa quebra é inevitável, como nos ensinou Frantz Fanon em Os condenados da terra (1976): "A descolonização é sempre um fenômeno violento". Se, como argumenta, descolonizar é "mudar a ordem do mundo", é também "um programa de desordem absoluta. Mas não pode ser o resultado de uma operação mágica, de um abalo natural ou de um acordo amigável" (FANON, 1979, p.26). Como contraviolência que reage a uma violência primordial e maior, a hostilidade da descolonização "será proporcional à violência exercida pelo regime colonial contestado" (FANON, 1979, p.69).

Enquanto Fanon defendia a contraviolência em meio às lutas pela libertação das nações africanas do colonialismo, os artistas indígenas que estão decapitando Mário de Andrade e reantropofagizando Oswald de 
Andrade ou Tarsila do Amaral o fazem como uma espécie de vingança que, mais do que nos aniquilar, nos responsabiliza. Como adverte a artista Jota Mombaça, a violência das diversas estratégias de luta anticolonial em curso se dá para "bagunçar o modo como a violência foi socialmente distribuída" (MOMBAÇA, 2017), "projetando sobre as posições até então isentas de marcas [raciais, sociais, étnicas, etc.] e, portanto, desigualmente inscritas como parte privilegiada do mundo como o conhecemos, a responsabilidade de confrontar a violência que dá forma a seu conforto ontológico” (MOMBAÇA, 2017). Por isso, a “(...) redistribuição da violência é um projeto de justiça social em pleno estado de emergência que deve ser performado por aquelas para quem a paz nunca foi uma opção" (MOMBAÇA, 2016).

\section{Guerra}

No documentário Guerras do Brasil.doc, Ailton Krenak, de frente para o entrevistador - e, consequentemente, para o espectador -, fulmina: "Nós estamos em guerra. Eu não sei por que você tá me olhando com essa cara tão simpática... Nós estamos em guerra. O seu mundo e o meu mundo estão em guerra. Os nossos mundos estão todos em guerra. A falsificação ideológica que sugere que nós temos paz é pra gente continuar mantendo a coisa funcionando... Não tem paz em lugar nenhum. É guerra em todos os lugares, o tempo todo" (KRENAK, 2018).

Escancarando a já evidente guerra, avizinha-se à perspectiva teorizada por Pierre Clastres em Arqueologia da violência: a guerra nas sociedades primitivas (1977), ensaio que conduz os leitores da presunção de que povos ameríndios seriam "sociedades contra a violência" à "conclusão de que são sociedades-para-a-guerra", elaborando uma teorização que, ao encarar o fato da guerra de modo ampliado, sublinha as diversas implicações de um estado de guerra permanente. Como dão a ver as estratégias de intimidação e a vontade de vingança da arte indígena dita brasileira contra a tradição da dita arte contemporânea do Brasil, a guerra não seria apenas uma reação ou defesa; ela é também ofensiva: portanto, tem "um fim político" (CLASTRES, 1977, p.186).

Essa perspectiva não-pacifista encontra desdobramentos nevrálgicos na antropologia atualmente desenvolvida no Brasil em seu reposicionamento do canibalismo para além dos devires pacifistas e culturalizantes comumente a ela atribuídos - o "tornar-se outro" e, ainda mais superficialmente, o "tornar-se um". Enquanto ronda, entre o outro e o um, uma espécie de fantasma hegeliano, Eduardo Viveiros de Castro faz ver que o complexo do canibalismo guerreiro

permitia nem mais nem menos que a perpetuação da vingança. (...) O ódio mortal a ligar os inimigos era o sinal de sua mútua indispensabilidade; este simulacro de exocanibalismo consumia os indivíduos para que seus grupos mantivessem o que tinham de essencial: sua 
relação ao outro, a vingança como conatus vital (VIVEIROS DE CASTRO, 2011, p.232-234).

Nesse sentido, matar, comer e vingar produziam menos um corpooutro ou único do que tempo: "só quem está para matar e quem está para morrer é que está efetivamente presente, isto é, vivo" (VIVEIROS DE CASTRO, 2011, 238).

Matar e vingar - guerrear - salvaguardam, nesses termos, a independência política. "Enquanto há guerra, há autonomia", afirma Clastres, sublinhando a importância de sua continuidade: "é por isso que ela não pode parar, que ela é permanente" (CLASTRES, 1977, p.201). Ao constantemente sabotar, por meio da guerra, a possibilidade de fixação do poder em algum grupo ou indivíduo, tais sociedades estão a exercer outros modos de poder. Não Ihes faltam uma ideia de Estado, esclarece Clastres. Ao contrário: é para evitar o Estado que se mantêm em guerra, dispersando-se continuamente e produzindo, assim, "uma sociedade contra o Estado" (CLASTRES, 1977, p.203).

Por sua vez, no ensaio Do etnocídio (1974), Clastres relaciona politicamente a ideia de Estado com a "destruição sistemática de modos de vida e de pensamento de pessoas diferentes daquelas que conduzem a empresa da destruição" (CLASTRES, 1974, p.53), posto que, tal como a perspectiva etnocêntrica que destrói a diferença do outro (ou o outro em sua diferença, como no genocídio), também o Estado "dissolve o múltiplo no Um", "força centrípeta que tende a esmagar as forças centrífugas inversas, quando as circunstâncias o exigem". Por isso, para o antropólogo, "a prática etnocidária e a máquina estatal funcionam da mesma maneira e produzem os mesmos efeitos", na medida em que "a cada desenvolvimento do poder central corresponde uma expansão maior do mundo cultural" (CLASTRES, 1974, p.57) por meio de processos de homogeneização cultural, a exemplo da unificação linguística. Sobre o guarda-chuva jurídico da igualdade - "todos são iguais perante a Lei" - o Estado produz a morte da diferença enquanto, perversamente, a supõe uma medida integradora:

O etnocídio (...) admite a relatividade do mal na diferença. Os outros são maus, mas podemos melhorálos, obrigando-os a transformarem-se até se tornarem, se possível, idênticos ao modelo que Ihes propomos, que Ihes impomos. A negação etnocidária do Outro conduz a uma identificação consigo mesmo. (...) A atitude etnocidária é antes de tudo otimista. (...) O etnocídio se exerce para o bem do Selvagem. (...) Na perspectiva de seus agentes, 0 etnocídio não poderia ser um empreendimento de destruição. É, ao contrário, uma tarefa necessária, exigida pelo humanismo, inscrito no coração da cultura ocidental. (CLASTRES, 1974, p.5458)

É diante desse pano de fundo ético, moral e político que, por sua vez, tem se dado a inscrição da arte contemporânea indígena no campo 
branco, burguês e europeu da arte contemporânea em seus campos hegemônicos. Como adverte Jaider Esbell, "o sistema de arte é algo paralelo [à arte indígena] e hoje eles se tocam" (ESBELL, 2019, p.98), mas são, como pondera Spivak acerca das duas formas de representação ("falar por" e "re-presentação"), "irredutivelmente descontínuos". Forjar equivalência entre esses distintos (e, em si, também diversos) regimes de arte é, portanto, violentá-los onto-epistemologicamente.

Como uma espécie de espelho do Estado etnocida, diante da tendência da arte em centripetamente tudo incluir através de processos de correspondência e homogeneização, o desafio que nos interpela ainda parece ser "como incluir sem integrar?": a velha e central problemática das 'políticas indigenistas' do Estado que, agora, com as medidas do Governo Bolsonaro e seu discurso de "integração nacional", voltam a assombrar o Brasil.

\section{Outras divisas}

"Produzir ou morrer" foi a "divisa do Ocidente" (CLASTRES, 1974, p.61) aos indígenas violentados pelo projeto colonial, cuja recusa a integrar-se ao regime de produção capitalista do colonizador implicava, necessariamente, genocídio. Por outro lado, produzir de acordo com a Lei do Estado para conseguir sobreviver a ele levou ao etnocídio, impedindo, criminalizando e punindo modos autônomos e divergentes de produção de sentidos, de crenças e de valores. Resulta daí que o sobrevivente do genocídio e do espistemicídio da colonização é, em grande parte, um indivíduo ontologicamente saqueado do pleno direito - histórico e contemporâneo - de si mesmo. Nesse cenário, ser artista e "resistir declaradamente com a arte" pode engendrar, por seu turno, um complexo de "ressignificação (...) de estruturas culturais e sociais com arte e espiritualidade em um mútuo alimentar de energias para compor a grande urgência de sustentar o céu acima de nossas cabeças" (ESBELL, 2019, p.104), desde que, evidentemente, possam escapar à atualização neocolonial, no âmbito da arte e seus agenciamentos, do duopólio "produzir ou morrer".

Nessa direção, parece urgente que a arte não-indígena interessada em constituir outros modos de lidar com a alteridade engaje-se antietnocentricamente na luta em curso contra o atual estado da arte e, inextricavelmente, contra a arte como Estado. Se romper com o poder centrípeto - da concentração de renda às normatividades estéticas - pode abrir espaço para uma inclusão não integracionista, por outro lado, incluir sem vingar pode, em seu "otimismo" (CLASTRES, 1974, p.61) etnocida e missionário, vir a novamente "legitimar as condições que levaram à

\footnotetext{
${ }^{9}$ Sobre as recentes medidas do Governo, ver Após transferir demarcações para Agricultura, Bolsonaro diz que vai 'integrar' indios e quilombolas (disponível em:

https://g1.globo.com/politica/noticia/2019/01/02/bolsonaro-diz-que-vai-integrar-indios-e-

quilombolas.ghtml) e 'Cada vez mais, o índio é um ser humano igual a nós', diz Bolsonaro (disponível em: https://oglobo.globo.com/brasil/cada-vez-mais-indio-um-ser-humano-igual-nos-diz-bolsonaro-124208483).
} 
Espaço Ameríndio

supressão da possibilidade de realidades alternativas, agora identificadas como ausências" (SANTOS, 2017, p.203). Todavia, posições como as de Denilson Baniwa com sua pintura ReAntropofagia parecem estar a nos dizer que, agora, se confrontados com o dilema "produzir ou morrer", terá chegado a hora de matar. 
Espaço Ameríndio

\section{Referências Bibliográficas}

ANDRADE, Mário de. Macunaíma: o herói sem nenhum caráter (1928). Chapecó: Ed. UFFS, 2019.

ANDRADE, Oswald de. Manifesto Antropófago (1928). In: TELES, Gilberto Mendonça. Vanguarda européia e modernismo brasileiro: apresentação e crítica dos principais manifestos vanguardistas. $3^{\mathrm{a}}$ ed. Petrópolis: Vozes; Brasília: INL, 1976.

ANDRADE, Oswald de. Prefácio a Serafim Ponte Grande (1933). 8. ed. São Paulo: Globo, 2001.

BANIWA, Denilson; GRADELLA, Pedro. Texto curatorial da mostra ReAntropofagia. Centro de Artes da Universidade Federal Fluminense. Niterói, março de 2019.

BANIWA, Denilson. [Depoimento] Quem sou eu? (2018). Apresentado oralmente em situações públicas. [Transcrição da autora] (2018b)

BANIWA, Denilson. Performance Pajé-Onça hackeando a 33 ${ }^{\text {a }}$ Bienal de Artes de São Paulo. São Paulo, 17 de novembro de 2018. Disponível em: https://www.youtube.com/watch?v=MGFU7aG8kgI. Acessado em 10 de fevereiro de 2020. [Transcrição da autora]

BELAUSTEGUIGOITIA, Marisa. Descarados y deslenguadas: el cuerpo y la lengua índia en los umbrales de la nación. Debate Feminista, Cidade do México, ano 12, vol. 24, outubro 2001.

CESARINO, Pedro. Os ameríndios e a incerteza na arte contemporânea. Arte!Brasileiros, São Paulo, 27/9/2016. Disponível em: http://brasileiros.com.br/hxZyl. Acesso em 10 de agosto de 2019.

CHIARELLI, Tadeu. Tarsila Populista. Revista Select, 12 de junho de 2019. Disponível em: https://artebrasileiros.com.br/opiniao/tarsila-populista/. Acessado em 5 de agosto de 2019.

CLASTRES, Pierre. Arqueologia da violência: a guerra nas sociedades primitivas (1977). In: Arqueologia da violência: ensaios de antropologia política. São Paulo: Ed. Brasiliense, 1980.

CLASTRES, Pierre. Do etnocídio (1974). In: Arqueologia da violência: ensaios de antropologia política. São Paulo: ed. Brasiliense, 1980.

DUSSEL, Enrique. Europa, modernidade y eurocentrismo. In: LANDER, Eduardo (comp.). La colonialidad del saber: eurocentrismo y ciências sociales. Perspectiva latino-americanas. Buenos Aires: CLASCO, 2000. [Tradução da autora] 
Espaço Ameríndio

ESBELL, Jaider. [Depoimento] Encontro Arte Indígena. Discussão sobre criação, produção e disseminação cultural indígena. São Paulo, Instituto Goethe, 2 de dezembro de 2017. Arquivo da autora.

ESBELL, Jaider. [Depoimento] Jaider Esbell expõe 'TransMakunaima' na Casa das Artes, em Manaus. Amazônia Real, Manaus, 25/05/2018. Disponível em: http://amazoniareal.com.br/jaider-esbell-expoe-transmakunaima-na-casa-das-artes-emmanaus/. (2018b)

ESBELL, Jaider. Arte indígena contemporânea e o grande mundo. Revista Select, São Paulo, ano 07, edição 39. Jun/jul/ago, 2019.

ESBELL, Jaider. Makunaima, o meu avô em mim! Iluminuras, Porto Alegre, v. 19, n. 46, p. 11-39, jan/jul, 2018.

FANON, Frantz. Os Condenados da Terra. Rio de Janeiro: Civilização Brasileira, 1979.

HERENHOFF, 1998. [Depoimento a] Celso Fioravante. Bienal é mais Brasil. Folha de São Paulo, São Paulo, 2/10/1998. Disponível em: https://www1.folha.uol.com.br/fsp/especial/fj02109801.htm. Acessado em 10 de janeiro de 2020.

KRENAK, Ailton. [Depoimento] Encontro Arte Indígena. Discussão sobre criação, produção e disseminação cultural indígena. São Paulo, Instituto Goethe, 2 de dezembro de 2017. Arquivo da autora.

KRENAK, Ailton. [Entrevista em] As Guerras da Conquista. In: Guerras do Brasil.doc. Direção de Luiz Bolognesi. NETLIX, 2018. Trecho da entrevista disponível em: https://www.youtube.com/watch?v=hM01D91hBn0. Acessado em 10 de janeiro de 2020. [Transcrição da autora]

MOMBAÇA, Jota. Notas estratégicas quanto aos usos políticos do conceito de lugar de fala. 19 de julho de 2017. Disponível em: http://www.buala.org/pt/corpo/notasestrategicas-quanto-aos-usos-politicos-do-conceito-de-lugar-de-fala. Acessado em 7 de agosto de 2019.

MOMBAÇA, Jota. Rumo a uma redistribuição desobediente de gênero e anticolonial da violência. Oficina de Imaginação Política e 32a Bienal de São Paulo, São Paulo, 2016. Disponível em: https://issuu.com/amilcarpacker/docs/rumo a uma redistribuic a o da vi. Acessado em 7 de agosto de 2019.

ROUSSEFF, Dilma. Discurso de recepção ao presidente Barack Obama. Brasília, 20/03/2011. Disponível em http://www.estadao.com.br/noticias/impresso,integra-dodiscurso-de-dilma-rousseff-na-recepcao-a-barack-obama,694534,0.htm. Acessado em 1 de agosto de 2019.

SANTOS, Boaventura de Sousa. Justicia entre saberes: epistemologias do Sul contra o epistemicídio. Madrid: Ediciones Morata, 2017. 
Espaço Ameríndio

SANTOS, Boaventura de Sousa. Para um novo senso comum: a ciência, o direito e a política na transição paradigmática. In: A crítica da razão indolente: contra o desperdício da experiência. São Paulo: Cortez, 2007.

SOARES DO BEM, Arim. Dominação da subjetividade e repressão à religiosidade africana: uma práxis transatlântica secular. In: Revista Kulê-Kulê. Maceió: EDUFAL, janeiro de 2008 .

SPIVAK, Gayatri Chakravorty. Pode o subalterno falar? (1988). Belo Horizonte: Editora UFMG, 2010.

VIVEIROS DE CASTRO, Eduardo. A inconstância da alma selvagem. São Paulo: Cosac Naify, 2011.

VIVEIROS DE CASTRO, Eduardo. O mármore e a murta: sobre a inconstância da alma selvagem. In: A inconstância da alma selvagem. São Paulo: Cosac Naify, 2011. 